Original Article

\title{
A study on macronutrient self-selection after acute aerobic exercise in college females
}

Tae-Young Kim, $\mathrm{PhD}^{1) a}$, Min-Jeong Kim, $\mathrm{PhD}^{1) a}$, Ik-Rae Cho, $\mathrm{PhD}^{1)}$, Yu-Mi Won, $\mathrm{PhD}^{1)}$, Mi-Kyung Han, PhD ${ }^{1}$, Kon-Nym Jung, PhD ${ }^{1)}$, Sang-Ho Lee, PhD $^{1)}$, Jae-Hee Lee, PhD ${ }^{1)}$, Ji-Hyoung Chin, PhD ${ }^{1}$, Jae-Hun Roh, PhD ${ }^{1}$, Seung-Hi Min, PhD ${ }^{1)}$, Taek-Kyun Lee, PhD $^{11}$, Hyo-Joo Park, MS ${ }^{1}$, Kwon Jang, PhD $^{2)}$, Se-Jeong Kwon, PhD $^{3)}$, Suh-Jung Kang, $\mathrm{PhD}^{4)}$, Mi-Ae Shin, $\mathrm{PhD}^{5}$, Hu-Nyun Kim, $\mathrm{PhD}^{5}$, Jae-Seung Hong, $\mathrm{PhD}^{6}$, Eun-Hi Chol, $\mathrm{MD}^{7)}$, Nam-Il An, $\mathrm{PhD}^{8}$, Ji-Hyuk KIm, PhD ${ }^{9)}$, Mi-Suk KIm, $\mathrm{PhD}^{9)^{*}}$

1) Department of Physical Education, College of Education, Hankuk University of Foreign Studies, Republic of Korea

2) Department of Taekwondo, Korea National Sport University, Republic of Korea

3) Major of Recreation and Leisure Sports, College of Sports Science, Chung-Ang University, Republic of Korea

4) Department of Exercise and Health Sciences, College of Natural Sciences, Sang Myung University, Republic of Korea

5) College of Creative Future Talent, Daejin University, Republic of Korea

6) Department of Physical Education, College of Natural Sciences, Hallym University, Republic of Korea

7) Department of Rehabilitation Medicine, College of Medicine, Hallym University, Republic of Korea

8) College of Humanities, Korea University, Republic of Korea

9) Department of Dance Art, Convergence Culture and Arts, Sungshin Women's University: Bomun-ro, 34 Da-gil, Seongbuk-gu, Seoul 02844, Republic of Korea

\begin{abstract}
Purpose] This study was conducted to determine whether acute aerobic exercise (climbing) is associated with changes in the dietary intake pattern. [Subjects and Methods] Food intake and physical activity data for 15 female college students were sampled for 3 days and categorized according to routine activity or high-intensity activity such as hiking. Nutrient intake based on the data was analyzed using a nutrition program. [Results] Carbohydrate and protein intake was significantly decreased after exercise compared to before acute aerobic exercise, but lipid intake showed no significant difference. Calorie intake was significantly decreased after exercise compared to before exercise; however, calorie consumption was significantly increased after exercise. [Conclusion] Aerobic exercise causes a decrease in total calories by inducing reduction in carbohydrate and protein intake. Therefore, aerobic exercise is very important for weight (body fat) control since it causes positive changes in the food intake pattern in female students.

Key words: Aerobic exercise, Macronutrient self-selection, Calorie
\end{abstract}

(This article was submitted Feb. 26, 2016, and was accepted May 26, 2016)

\section{INTRODUCTION}

An interest in diets has recently increased among female students. However, inappropriate diets have adverse effects on

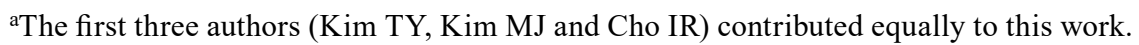

*Corresponding author: Mi-Suk Kim (E-mail: mshb0320@naver.com)

(C2016 The Society of Physical Therapy Science. Published by IPEC Inc.

This is an open-access article distributed under the terms of the Creative Commons Attribution Non-Commercial No Derivatives (by-nc-nd) License $<$ http://creativecommons.org/licenses/by-nc-nd/4.0/>. 
health. A major reason why a diet may fail is an imbalance between energy intake and consumption. The amount of energy consumption is generally smaller than that of energy intake. Thus, further research is needed on this relationship.

Physical activity (exercise) helps decrease body fat as energy consumption increases. The food intake pattern can reduce fat intake.

In a study of post-exercise macronutrient self-selection (MNSS), male mice were subjectd to a 40-day regimen of training (6-7 km/day) at low intensity and were allowed free access to carbohydrate, lipid, and protein feed. Lipid and protein intake increased, but carbohydrate intake decreased ${ }^{1}$. After a regimen of 2-hour endurance exercise in Wistar rats at a speed of 15 $\mathrm{m} / \mathrm{min}$, the total energy intake was significantly decreased. The findings showed a decrease in carbohydrate and protein intake after exercise and in lipid intake over time, leading to a decrease in total energy intake ${ }^{2}$.

When a swimming exercise program was performed for 4 months in male and female rats according to age $(4,6,12,16$, and 23 months) and dietary intake was observed, total calorie intake increased more in female rats than in male rats with increasing age. This indicated that the central nervous system's control of diet deteriorated with aging ${ }^{3)}$. In addition, when a 4-week program of swimming and running exercise was performed in male white rats, the total energy intake was in the order of the control group, swimming exercise group, and running exercise group, and showed that exercise on the ground was significantly more beneficial than exercise in water ${ }^{4}$. However, studies regarding dietary choice after physical activity were mostly conducted in animals. In a study conducted in humans, trained cycling athletes were adapted to a 2-week high-lipid diet and exercise ranging from moderate to high intensity was performed by the subjects; the results showed an increase in carbohydrate tolerance that led to a delay in the onset of fatigue ${ }^{5)}$. These studies might help explain the mechanism of physical metabolism through exercise with dietary intake adaptation, but did not provide any valuable information about strategies for effective dietary intake.

Thus, this study was conducted to analyze dietary intake patterns in female college students with an interest in diet and to verify the effects of temporary physical activity on energy intake in order to provide data for correct diet and body fat reduction. The study was designed to verify the effects of aerobic exercise on the selection of dietary intake by comparing and analyzing calorie intake and consumption (carbohydrate, lipid, protein, and total calories) during aerobic exercise (climbing); a reference point was set after analyzing daily calorie intake and consumption in female college students using Computer Aided Nutritional analysis program 3.0 for Professionals (CAN-Pro 3.0), which was certified by the Korean Nutrition Society ${ }^{6}$.

\section{SUBJECTS AND METHODS}

Baseline height, weight, and body fat were measured with the Inbody 520 (Biospace, Korea) in subjects who were aware of the study objectives (Table 1).

To investigate the usual dietary intake patterns of female college students, a questionnaire developed by the author on the amount of food intake and amount of physical activity was distributed to the subjects; they were asked to complete the questionnaire with respect to information on the type of food intake and the weight of the food for 3 days. The subjects were also instructed to photograph the food before and after a meal (breakfast, lunch, and dinner) and to send a total of 6 photographs per day to the investigator (phone or email).

One week later, another questionnaire was distributed to the participants to investigate the amount of food intake and the amount of physical activity during exercise. The investigation method was the same as that for usual food intake, and included asking subjects to record the parameters for 3 days and to send photographs of food before and after a meal to the investigator. Physical activity during the same period included aerobic exercise at moderate intensity: 1 hour of group climbing. During climbing, 1 researcher stayed at the front and 1 at the rear to ensure pace adjustment so that no one was left behind or went off the trail.

Body weights (Xiaomi Co., China) before and after sleep were measured and recorded on the questionnaire. The same model of scale was provided to all subjects to accurately measure and record the parameters.

CAN-Pro 3.0, a program developed for assessment of nutrient intake in the Korean population, was used by applying the Dietary Reference Intakes for Koreans (KDRIS), which was revised by the Korean Nutrition Society in 2007. The Nutrient Database (NDB) was very helpful to ensure accuracy in the assessment of nutrient intake; data included basic nutrients as well as micronutrients in food.

Using this program, this study analyzed the nutrients consumed ( 3 meals and snacks) by individual subjects with CAN-Pro 3.0 food codes based on the food intake questionnaire sheet collected from the subjects; the amount of intake of each nutrient was calculated using the NDB.

Table 1. Physical characteristics of female college students

\begin{tabular}{cccccc}
\hline Variable & Age $(\mathrm{yrs})$ & Weight $(\mathrm{kg})$ & Height $(\mathrm{cm})$ & Fat $(\%)$ & BMI $\left(\mathrm{kg} / \mathrm{m}^{2}\right)$ \\
\hline & $19.5 \pm 1.3$ & $53.8 \pm 5.6$ & $160.2 \pm 4.4$ & $28.5 \pm 6.0$ & $21.0 \pm 1.9$ \\
\hline
\end{tabular}

BMI: body mass index 
This study was approved by the ethics committee of the Hankuk University of Foreign Studies (IRB No. HIRB-201504HR-002), and written consent for participation in the study was obtained from all subjects in accordance with the Declaration of Helsinki.

The results of each metric were calculated as the mean and standard deviation by using Statistical Package for the Social Sciences (SPSS) Windows version 18.0 and a paired t-test was used to determine pre-exercise and post-exercise differences; the statistical significance level was set at $\mathrm{p}<0.05$.

\section{RESULTS}

The study was conducted in 15 healthy female university students, with physical characteristics shown in Table 1 .

The mean age was 19.5 years, the mean weight was $53.8 \mathrm{~kg}$, the mean height was $160.2 \mathrm{~cm}$, the body fat was $28.5 \%$, and the body mass index (BMI) was $21.0 \mathrm{~kg} / \mathrm{m}^{2}$. The results of analysis of pre- and post-exercise differences are shown in Table 2.

Carbohydrate intake $(826.8 \mathrm{kcal})$ decreased significantly $(\mathrm{p}<0.05)$ after aerobic exercise (climbing) compared to carbohydrate intake $(1,005.4 \mathrm{kcal})$ before aerobic exercise (climbing); post-exercise protein intake (286.1 kcal) was significantly decreased compared to pre-exercise protein intake $(753.3 \mathrm{kcal})(\mathrm{p}<0.001)$. However, lipid intake showed no significant differences before and after aerobic exercise (climbing).

The analysis of differences in pre- and post-exercise total calorie intake and total calorie consumption is shown in Table 3 .

Total calorie intake $(2,012.6 \mathrm{kcal})$ before aerobic exercise (climbing) was significantly $(\mathrm{p}<0.05)$ higher than total calorie intake $(1,694.1 \mathrm{kcal})$ after exercise; pre-exercise total calorie consumption $(1,126.6 \mathrm{kcal})$ was significantly lower than postexercise total calorie consumption $(1,221.4 \mathrm{kcal})(\mathrm{p}<0.05)$.

\section{DISCUSSION}

This study was conducted to examine the change in dietary intake pattern according to the level of activity and exercise in female college students, as well as to determine the positive effects of health promotion and changes in weight and body fat.

Free intake was recommended in subjects who performed aerobic exercise in relation to the type of food intake volume; however, it is known that the type of food intake affects the pattern of cardiovascular metabolism ${ }^{7}$. In particular, while performing cardiovascular exercise, different respiratory exchange ratios (RER) appear in accordance with the type of food intake; therefore, it is important to carefully consider whether the food intake is in liquid or solid form ${ }^{8)}$. When the food is in solid instead of liquid form, blood flow, pulse rate, systolic blood pressure, and cardiac output ${ }^{8-11)}$ increase, with changes in the sympathetic nervous system ${ }^{8,10)}$ and hormonal responses ${ }^{9)}$.

In this study, because we did not analyze the energy (calories) consumption related to the type of food intake, we were only able to assess trends in overall energy consumption in terms of calories. A significant decrease in calorie intake was observed after aerobic exercise compared to before aerobic exercise, due to a significant decrease in protein and carbohydrate intake. Lipid intake also showed a decrease, but there was no significant difference before and after exercise. These results were consistent with a previous study ${ }^{2,6}$, conducted in rats, which showed significant differences in carbohydrate, lipid, and protein intake before and after aerobic exercise. Protein intake showed the greatest decrease, such that the proportion of total energy intake was decreased. This suggests that performing physical activity could decrease the food intake.

A study showed that the longer young people sat down to watch TV or to play computer games, the greater the decrease in total energy consumption, whereas BMI and body fat increased to higher levels ${ }^{12}$; ; the study was conducted in 180 young students from Saudi Arabia (males and females). The same study showed that $67.5 \%$ of the highly obese patients included adults who performed little physical activity and worked in a sitting position on a sofa or a chair ${ }^{13}$. However, as there is an increasing trend in obesity among all age groups, significant attention has been paid to weight loss and body fat reduction. Nevertheless, even when subjects have high interest in weight (body fat) control, they may lack commitment and ability to control their weight for health management. Weight control in female college students involves the universal use of food therapy, exercise therapy, medical therapy, and behavioral therapy; among these methods, exercise therapy shows the most

Table 2. Pre- and post-exercise differences in carbohydrate, protein, and lipid intake in female college students (unit: kcal)

\begin{tabular}{lrl}
\hline Variable & \multicolumn{1}{c}{ Pre-test } & \multicolumn{1}{c}{ Post-test } \\
\hline Carbohydrate intake & $1,005.4 \pm 355.3$ & $826.8 \pm 292.7^{*}$ \\
Protein intake & $753.3 \pm 382.5$ & $286.1 \pm 125.2^{* * *}$ \\
Lipid intake & $630.5 \pm 262.7$ & $581.2 \pm 273.8$ \\
\hline
\end{tabular}

Values are expressed as mean \pm standard deviation; $* \mathrm{p}<0.05$,

$* * * p<0.001$ : significant difference pre- and post-exercise
Table 3. Pre- and post-exercise differences in total calorie intake and total calorie consumption in female college students (unit: kcal)

\begin{tabular}{lcc}
\hline Variable & Pre-test & Post-test \\
\hline Total calorie intake & $2,012.6 \pm 678.4$ & $1,694.1 \pm 579.4^{*}$ \\
Total calorie consumption & $1,126.6 \pm 228.1$ & $1,221.4 \pm 184.6^{*}$ \\
\hline
\end{tabular}

Values are expressed as mean \pm standard deviation; $* \mathrm{p}<0.05$ : significant difference pre- and post-exercise 
economical, safest, and greatest effects; hence, this draws the attention of all female students ${ }^{14)}$. In recent years, the mass media reported the effects of yoga (Pilates) in addition to aerobic exercise for healthy body shape in women, and encouraged continued exercise therapy for several months, depending on the physical condition and strength of the subjects. Although the results vary depending on individual physical condition, exercise therapy gradually shows effectiveness after 4 weeks, and the effectiveness is increased after 8 weeks. When exercise therapy is performed for 12 weeks, the body is reshaped and proportionally balanced with reduced body fat and increased muscle strength. In addition, exercise therapy improves the levels of total cholesterol and triglycerides, and induces positive changes in hormone and enzyme levels. Therefore, exercise that improves the basal metabolic rate by decreasing body fat and increasing the muscle mass through a combination of aerobic exercise and muscular strength training was recently recommended ${ }^{15}$.

In a comparison of post-acute aerobic exercise with post-breakfast aerobic exercise in order to examine the use of energy substrates and changes in hormone levels, post-fasting aerobic exercise was found to be far more effective in decreasing body fat ${ }^{16)}$. As noted above, it was found that the timing of food intake is very important in the study of aerobic exercise and food intake.

In conclusion, aerobic exercise causes reduction in total calories by decreasing lipid and protein intake, and is very important for weight (body fat) control, by inducing positive changes in the dietary pattern in female college students. However, in future studies, issues related to the 24-hour subject control method should be addressed, together with accurate measurements of nutrient intake and consumption.

\section{ACKNOWLEDGEMENT}

The paper was supported by 2016 Sungshin Women's University’s school support for scientific Research.

\section{REFERENCES}

1) Andik I, Bank J, Moring I, et al.: The effect of exercise on the intake and selection of food in the rat. Acta Physiol Hung, 1954, 5: 457-461. [Medline]

2) Larue-Achagiotis C, Martin C, Verger P, et al.: Effects of acute treadmill exercise and delayed access to food on food selection in rats. Physiol Behav, 1993, 53 : 403-408. [Medline] [CrossRef]

3) Boghossian S, Veyrat-Durebex C, Alliot J: Age-related changes in adaptive macronutrient intake in swimming male and female Lou rats. Physiol Behav, 2000, 69: 231-238. [Medline] [CrossRef]

4) Kim H, Kim TY: Effects of aerobic exercise on macronutrient self-selection in rats. Korean J Nutr, 2000, 33: 794-801.

5) Lambert EV, Speechly DP, Dennis SC, et al.: Enhanced endurance in trained cyclists during moderate intensity exercise following 2 weeks adaptation to a high fat diet. Eur J Appl Physiol Occup Physiol, 1994, 69: 287-293. [Medline] [CrossRef]

6) Shim YJ, Paik HY: Reanalysis of 2007 Korean national health and nutrition examination survey (2007 KNHANES) Results by CAN-Pro 3.0 Nutrient Database. Korean J Nutr, 2009, 42: 577-595. [CrossRef]

7) Yokogawa M, Ueda K, Murase J, et al.: Effects of food intake on physiological responses to cardiopulmonary exercise testing. J Phys Ther Sci, 2007, 19: 145-150. [CrossRef]

8) Rokowski RJ, Spodick DH: Prandial effects on cardiac function and responses. Am Heart J, 1989, 118: 1078-1082. [Medline] [CrossRef]

9) Cornyn JW, Massie BM, Unverferth DV, et al.: Hemodynamic changes after meals and placebo treatment in chronic congestive heart failure. Am J Cardiol, 1986, 57: 238-241. [Medline] [CrossRef]

10) Kelbaek H, Gjørup T, Christensen NJ, et al.: Central hemodynamic changes after ingestion of a meal in patients with coronary artery disease. Arch Intern Med, 1989, 149: 363-365. [Medline] [CrossRef]

11) Fagan TC, Sawyer PR, Gourley LA, et al.: Postprandial alterations in hemodynamics and blood pressure in normal subjects. Am J Cardiol, 1986, 58: 636-641. [Medline] [CrossRef]

12) Alghadir AH, Gabr SA, Iqbal ZA: Effects of sitting time associated with media consumption on physical activity patterns and daily energy expenditure of Saudi school students. J Phys Ther Sci, 2015, 27: 2807-2812. [Medline] [CrossRef]

13) Korea Obesity Academic Society: Clinic Obesity. Seoul: Korea Medicine, 2001.

14) An MY: The effect on fat, TCHO, glucose and TG of middle-aged women by regular exercise. KAHPERD, 2000, 39: 351-358.

15) Lee HC, Heo T: Effects of exercise therapy on blood lipids of obese women. J Phys Ther Sci, 2014, 26: 1675-1677. [Medline] [CrossRef]

16) Kim TW, Lee SH, Choi KH, et al.: Comparison of the effects of acute exercise after overnight fasting and breakfast on energy substrate and hormone levels in obese men. J Phys Ther Sci, 2015, 27: 1929-1932. [Medline] [CrossRef] 